\title{
Treatment of patients with Mayer-Rokitansky- Küster-Hauser syndrome in a tertiary hospital
}

\author{
Karen Ng *, Patricia NP Ip, KW Yiu, Jacqueline PW Chung, Symphorosa SC Chan
}

\section{A B S T R A C T}

Introduction: Mayer-Rokitansky-Küster-Hauser $(\mathrm{MRKH})$ syndrome is an uncommon congenital malformation characterised by agenesis or hypoplasia of the vagina and uterus. Here, we describe the treatment of patients with $\mathrm{MRKH}$ syndrome in a tertiary hospital.

Methods: This retrospective study included patients with MRKH syndrome attending the Paediatric and Adolescent Gynaecology Clinic in a tertiary hospital. Their clinical manifestations, examinations, and methods for neovagina creation were recorded. Among patients who underwent vaginal dilation (VD), therapy duration, vaginal width and length at baseline and after VD, complications, and sexual activity and dyspareunia outcomes were evaluated.

Results: Forty nine patients with MRKH syndrome were identified. Their mean age at presentation was 17.9 years; $69.4 \%$ and $24.5 \%$ of patients presented for primary amenorrhoea treatment and vaginoplasty, respectively. Forty eight patients had normal renal imaging findings and 46 XX karyotypes. Seventeen $(34.7 \%)$ patients underwent VD as first-line therapy;

three did not complete the therapy. Two had surgical length by sexual intercourse alone; 25 had not yet requested VD. The mean duration of VD was $16 \pm 10.2$ (range, 4-35) weeks. The widths and lengths of the vagina at baseline and after VD were $1.1 \pm 0.28 \mathrm{~cm}$ and $1.3 \pm 0.7 \mathrm{~cm}$, and $3.1 \pm 0.5 \mathrm{~cm}$ and $6.9 \pm 0.9 \mathrm{~cm}$, respectively. The overall success rate of VD was 92.3\%. Vaginal spotting was the most common complication (21\%); only one patient reported dyspareunia.

Conclusions: Mayer-Rokitansky-Küster-Hauser syndrome is an uncommon condition that requires multidisciplinary specialist care. Vaginal dilation is an effective first-line approach for neovagina creation.

\section{Hong Kong Med J 2020;26:397-403 \\ https://doi.org/10.12809/hkmj208467}

K Ng *, FHKAM (Obstetrics and Gynaecology), FHKCOG

PNP Ip, MB, ChB

KW Yiu, FHKAM (Obstetrics and Gynaecology), FHKCOG

JPW Chung, FHKAM (Obstetrics and Gynaecology), FHKCOG

SSC Chan, MD, FHKCOG

Department of Obstetrics and Gynaecology, The Chinese University of Hong Kong, Prince of Wales Hospital, Shatin, Hong Kong

vaginoplasty, whereas five achieved adequate vaginal *Corresponding author: ngkaren@cuhk.edu.hk

New knowledge added by this study

- Most patients were diagnosed with Mayer-Rokitansky-Küster-Hauser (MRKH) syndrome after they presented with primary amenorrhoea. Most patients with MRKH syndrome exhibited normal renal imaging findings, but did not possess a uterus.

- Among patients with MRKH syndrome who completed vaginal dilation (VD) therapy, the success rate was $92.3 \%$, based on reports of subjective sexual satisfaction.

- The most common complication during VD therapy was vaginal spotting (21\% of patients), which resolved with conservative management or the use of vaginal oestrogen cream.

- For patients with MRKH syndrome who discontinued treatment prior to completion of VD therapy, a considerably shorter second course of treatment was sufficient to achieve satisfactory vaginal length.

Implications for clinical practice or policy

- Resources should be allocated for provision of psychological services, including the option for group-based therapy, because these may be helpful for patients with MRKH syndrome and their caregivers.

- VD therapy should be recommended as first-line treatment for the creation of a neovagina in patients with MRKH syndrome, following careful consideration of local expertise, patient preferences, and patient ability to maintain compliance for the duration of therapy.

\section{Introduction}

Mayer-Rokitansky-Küster-Hauser

(MRKH) syndrome is a congenital malformation characterised by failed development of the Müllerian duct, which leads to vaginal agenesis, often accompanied by uterine agenesis. It is estimated to occur in one in 4000 to 5000 births. ${ }^{1}$ Most patients present with primary amenorrhoea, but exhibit normal secondary sexual characteristics. Mayer-Rokitansky-KüsterHauser syndrome is reportedly associated with other malformations including renal, skeletal, and auditory manifestations. ${ }^{2,3}$ The creation of a functional neovagina is a component of treatment performed to aid women in achieving a normal sexual life. The 


\section{MRKH綜合徵患者於一家三級醫院的治療}

吳嘉詠、葉雅平、姚嘉樺、鍾佩樺、陳丞智

引言：MRKH綜合徵是一種罕見的先天畸形，其特徵是陰道和子宮發 育不全或異常。本研究描述一所三級醫院對MRKH綜合徵患者的治 療。

方法：這項回顧性研究納入一家三級醫院的兒科和青少年婦科診所就 診的MRKH綜合徵患者, 記錄他們的臨床表現、檢查和再生陰道形成 方法, 以及評估接受陰道頂壓延長法患者的治療時間、基線和術後陰 道的寬度和長度、併發症、性活動及性交疼痛的結果。

結果：鑑定49例MRKH綜合徵患者。入院時的平均年齡為 17.9 歲, 其 中 $69.4 \%$ 和 $24.5 \%$ 患者分別接受原發性閉經治療和陰道成形術治療。 48 例患者的腎臟影像學檢查正常, 染色體核型為46XX。1 7 例 (34.7\%) 患者接受陰道頂壓延長法作為一線療法；3人沒有完成 治療。2 例接受陰道成形術, 5 例僅透過性交便有滿意的再生陰道 長度。25例沒有要求陰道頂壓延長法。陰道頂壓延長法平均持續 $16 \pm 10.2$ 週（介乎4-35週）。基線和陰道頂壓延長法後陰道的寬 度分別為 $1.1 \pm 0.28 \mathrm{~cm}$ 和 $1.3 \pm 0.7 \mathrm{~cm}$, 長度分別為 $3.1 \pm 0.5 \mathrm{~cm}$ 和 $6.9 \pm 0.9 \mathrm{~cm}$ 。陰道頂壓延長法的總體成功率為 $92.3 \%$ 。陰道出血是最 常見的併發症 $(21 \%)$ 。僅1名患者報告性交疼痛。

結論：MRKH綜合徵是一種罕見疾病, 需要多學科專家護理。陰道頂 壓延長法是組織再生陰道的有效一線療法。 timing for the creation of a neovagina depends on the patient. However, treatment should be deferred beyond late adolescence to allow each patient to provided informed consent and participate in the treatment process. ${ }^{4}$ Both surgical and non-surgical methods have been described for the creation of a neovagina. Regarding surgical options, various grafts or moulds may be used; other techniques include traction vaginoplasty. ${ }^{5}$ Surgical techniques often achieve anatomical success, but result in associated complications such as bladder injury, neovaginal vault granulation, introital stenosis, vaginal discharge, urinary tract infection, or graft infection. ${ }^{4,6,7}$ After most surgical techniques, patients often require postoperative utilisation of a mould or dilator. ${ }^{5}$

Despite the availability of many surgical methods, non-surgical methods with vaginal dilation (VD) are advocated as first-line treatment in many instances ${ }^{6,8}$; VD has been proven effective in the creation of a neovagina. ${ }^{5,9}$ Notably, data are available regarding surgical creation of a neovagina in the Chinese population ${ }^{10}$; however, there is limited information concerning the implementation of VD in the Chinese population, despite the recommendation of VD as first-line treatment for the creation of a neovagina. Chinese adolescents or their caregivers may prefer more conservative treatment options for MRKH syndrome. ${ }^{11,12}$ In addition, pelvic connective tissue has been proposed to differ between Chinese women and Caucasian women. ${ }^{13}$
In this study, we investigated the treatment of patients with MRKH syndrome, evaluated the effectiveness of VD therapy, and identified complications among patients with MRKH syndrome who underwent VD. To the best of our knowledge, this is the first report regarding VD therapy in Chinese women with MRKH syndrome in the English-language medical literature.

\section{Methods}

\section{Patient population and standard treatment}

A Paediatric and Adolescent Gynaecology Clinic has been established in our tertiary university teaching hospital since late 2002. All female patients with MRKH syndrome underwent treatment in that clinic by gynaecologists who specialised in paediatric and adolescent gynaecology. Generally, diagnosis was made on the basis of primary amenorrhoea, normal secondary sexual characteristics, vaginal absence, or vaginal dimple on perineal inspection. Ultrasound assessment showed that most patients also did not exhibit a uterus; when a uterus was present, it was either functioning or rudimentary. Thorough counselling concerning the diagnosis, including implications for future sexual life and fertility, was provided to the patients and their caregivers. Ultrasound or magnetic resonance imaging for the urinary system was performed to rule out urinary tract anomalies. Patients returned for examination a few weeks or months after the initial visit, then began annual follow-up. During further follow-up, patients received an explanation of vaginoplasty; they were encouraged to discuss whether the procedure was appropriate, following careful consideration.

\section{Data collection}

This retrospective observational study was performed using information from a prospectively collected database of all patients who had received treatment for MRKH syndrome in our clinic. The patients' medical notes were reviewed; demographic data, presenting symptoms, previous imaging findings, and history of sexual experience were recorded. The method of vaginal creation, if any, was also recorded. Regarding the outcome of VD therapy, patients who had undergone VD as the primary method for creation of a neovagina were included in the analysis. The number of sessions, the starting and final vaginal width and length, the interval until completion of therapy, and any complications associated with the therapy were reviewed. The outcomes of VD in terms of sexual activity, dyspareunia, and sexual satisfaction were reviewed.

\section{Vaginal dilation therapy}

Patients who requested VD therapy were scheduled for individual treatment sessions with 
the gynaecologist. For the first session, patients were admitted to the day ward; three intensive VD sessions were performed on the first day. The dilator (custom made by the Queen Charlotte and Chelsea Hospital, United Kingdom; another dilator set, the "Amielle Comfort vaginal dilators" manufactured by Owen Mumford was also used) was placed at the vaginal dimple and constant pressure was applied using the dilator for 15 minutes. The first session was performed by the gynaecologist, the second session was performed by the patient under medical supervision, and the third session was performed independently by the patient. The patient was discharged with instructions to perform two to three VD sessions per day at home, 15 minutes per session. Follow-up was arranged on an out-patient basis, at intervals of 2 to 4 weeks. Patients were provided with appropriately sized dilators, typically larger over time (Fig). Neovaginal width and length were recorded at each follow-up visit. Any complications and sexual function were also recorded. Vaginal dilation therapy was discontinued when a patient achieved satisfactory sexual intercourse.

\section{Data analysis}

SPSS Statistics for Windows, version 21.0 (IBM Corp, Armonk [NY], United States) was used to analyse the data collected. Normally distributed data are described as mean \pm standard deviation, whereas non-normally distributed data are described as median (range). Independent samples $t$ tests were used to compare results between two groups. $\mathrm{P}<0.05$ was considered statistically significant.

\section{Results}

\section{Patient characteristics and clinical treatment}

In total, 49 patients with MRKH syndrome underwent treatment in our clinic from 2002 to 2019. The mean

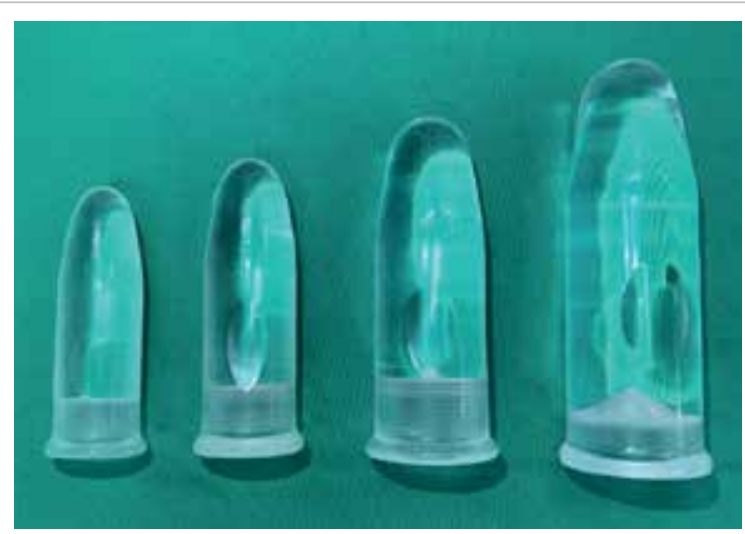

FIG. Vaginal dilators used for therapy in our clinic. (From left) Size I (length $75 \mathrm{~mm} \times$ diameter $25 \mathrm{~mm})$, Size $2(85 \mathrm{~mm} \times$ $30 \mathrm{~mm}$ ), Size $3(100 \mathrm{~mm} \times 35 \mathrm{~mm})$, and Size $4(110 \mathrm{~mm}$; $40 \mathrm{~mm}$ ) patient age at presentation was $17.9 \pm 4.9$ years (range, 11-36 years). Overall, 34 (69.4\%) patients presented with primary amenorrhoea and received diagnoses of MRKH syndrome in our clinic. The mean age among this group of patients was $16.7 \pm 2.4$ years. Another 12 (24.5\%) patients were referred for further treatment and/or VD therapy, following diagnosis in another clinic. Two (4.1\%) patients presented with acute surgical complications, torsion of ovarian cyst, and suspected appendicitis; the patients were diagnosed with hematometra and hematosalpinx at age 11 and 16 years, respectively, because of incidental intra-operative pelvic findings. Finally, one patient presented for labial minora hypertrophy at age 12 years and was incidentally diagnosed with vaginal agenesis during perineal examination. Forty eight of the 49 patients had a 46 XX karyotype; one patient had a 47 XXX karyotype. Two patients had a unilateral functioning uterus, while three patients had a non-functioning rudimentary uterine horn. Overall, 45 patients underwent imaging, either ultrasound or magnetic resonance imaging, to assess the renal system; some patients also underwent intravenous urography. Of these 45 patients, 44 had normal findings; one patient had a dilated pelvicalyceal system and ureter with suspected low insertion into the bladder, but no signs of obstruction were found. The remaining four patients were either waiting for the imaging appointment or did not have imaging information in their medical notes.

Overall, 17 (34.7\%) patients underwent VD therapy as first-line therapy for the creation of a neovagina. Two (4.1\%) patients had surgeries as first-line treatment: one patient underwent Creatsas vaginoplasty in our hospital and one underwent vaginoplasty at a hospital in China. Both of these two patients required VD therapy, at 12 years and 1 year, respectively, after their original surgeries because of vaginal stenosis. Furthermore, five (10.2\%) patients achieved creation of a neovagina by sexual intercourse alone. Finally, 25 (51\%) patients had not yet requested vaginoplasty; these patients were significantly younger than patients who had undergone vaginoplasty $(22.8 \pm 5.2$ years vs $30 \pm 7.0$ years, $\mathrm{P}<0.005)$ [Table]

\section{Vaginal dilation outcomes and follow-up}

Of the 17 patients who underwent VD therapy as first-line treatment, four (23.5\%) reported that they had previously attempted unsuccessful coitus and therefore requested VD therapy. For these four patients, the mean age at initiation of VD therapy was 24.4 \pm 5.7 years (range, $18-36$ years). The mean width and length of the vagina at baseline were $1.1 \pm 0.28 \mathrm{~cm}$ (range, $1-2 \mathrm{~cm}$ ) and $1.3 \pm 0.7 \mathrm{~cm}$ (range, $0.5-3 \mathrm{~cm})$, respectively. There were no differences in starting width and length between the four patients who had previously attempted coitus and the 
TABLE. Characteristics of patients with Mayer-Rokitansky-Küster-Hauser syndrome, stratified according to the type of vaginoplasty treatment*

\begin{tabular}{|c|c|c|c|c|}
\hline & \multicolumn{3}{|c|}{ Completed vaginoplasty } & \multirow{2}{*}{$\begin{array}{c}\text { No vaginoplasty } \\
\begin{array}{c}\text { No treatment yet } \\
(n=25)\end{array}\end{array}$} \\
\hline & $\begin{array}{l}\text { VD as first-line } \\
\text { therapy }(n=17)\end{array}$ & $\begin{array}{c}\text { Surgery as first-line } \\
\text { therapy }(n=2)\end{array}$ & $\begin{array}{l}\text { Coitus as first-line } \\
\text { therapy }(n=5)\end{array}$ & \\
\hline Age at this report (years) & $30.5 \pm 7.6$ & 21 and 32 & $29.8 \pm 5.0$ & $22.8 \pm 5.2$ \\
\hline Age at first consultation (years) & $20.4 \pm 6.4$ & 15 and 18 & $17.4 \pm 2.8$ & $16.5 \pm 3.5$ \\
\hline Age at vaginoplasty (years) & $24.4 \pm 5.7$ & 18 and 19 & $18.8 \pm 4.0$ & Not applicable \\
\hline \multicolumn{5}{|l|}{ Before VD therapy } \\
\hline Vaginal width (cm) & $1.1 \pm 0.3$ & 2.5 and 3.0 & Not available & Not applicable \\
\hline Vaginal length (cm) & $1.3 \pm 0.7$ & 4.0 and 5.0 & & \\
\hline After VD therapy & $(n=14) \dagger$ & & & \\
\hline Vaginal width (cm) & $3.1 \pm 0.5$ & 3.0 and 3.0 & $2.7 \pm 0.4$ & Not applicable \\
\hline Vaginal length (cm) & $6.9 \pm 0.9$ & 7.5 and 8.0 & $5.7 \pm 1.6$ & \\
\hline
\end{tabular}

remaining 13 who had not. Three patients did not complete VD therapy because their relationships had ended and they chose to discontinue the therapy. Among the patients who completed VD therapy, the final width and length of the vagina were $3.1 \pm 0.5 \mathrm{~cm}$ (range, 2-4 cm) and $6.9 \pm 0.9 \mathrm{~cm}$ (range, 6-9 cm), respectively. The mean interval until the completion of VD therapy was $16 \pm 10.2$ (range, 4-35) weeks. Notably, there was no difference in duration of VD therapy between patients who had and patients who had not previously attempted coitus before commencement of therapy $(\mathrm{P}=0.83)$.

Of the 14 patients who completed VD therapy, one was lost to follow-up; 13 were included in further analysis. All 13 of these patients were sexually active after VD therapy, and 12 reported subjective sexual satisfaction. Therefore, the success rate of VD therapy was $92.3 \%$ in our cohort. The remaining patient reported mild superficial dyspareunia and that the vaginal length of $6 \mathrm{~cm}$ was inadequate for achievement of sexual satisfaction; thus, surgical vaginoplasty is planned.

\section{Complications and subsequent therapy}

The most common complication during VD was vaginal spotting, which occurred in four (21\%) of the 19 patients who had undergone VD therapy. In all patients, spotting subsided with conservative management or the use of vaginal oestrogen cream. One patient had one episode of urinary tract infection, which resolved following treatment with oral antibiotics.

Among the three patients in the VD group who did not complete therapy when their relationships ended, all began a second course of VD therapy following new requests for treatment. The second course required a considerably shorter duration (4-8 weeks) to achieve satisfactory vaginal length for sexual intercourse.

\section{Findings after neovagina creation by coitus alone}

Among the five patients who achieved creation of a neovagina by coitus alone, their age at initial sexual intercourse ranged from 13 to 24 years. Their mean vaginal width and length were $2.7 \mathrm{~cm}$ and $5.7 \mathrm{~cm}$, respectively. One patient had a rectovaginal fistula; she reported faecal incontinence from the vagina and the passage of semen from the anus after sexual intercourse. Examination revealed a $5-\times 2-\mathrm{mm}$ rectovaginal fistula in the posterior vaginal wall, $3 \mathrm{~cm}$ above the introitus. Vaginal repair of the fistula was performed; the patient reported no further faecal incontinence nor abnormal passage of semen.

\section{Findings in patients with functioning endometrium}

Regarding the two patients with a functioning endometrium, one had a hysterectomy at age 18 years, shortly after she had undergone Creatsas vaginoplasty. The other patient had a unicornuate uterus that was initially suppressed with gonadotropin-releasing hormone analogue with supplemental oestrogen therapy until age 21 years; she then selected uterinepreserving surgery. After VD therapy, the patient underwent uterovaginal anastomosis by laparotomy and the perineal route. Two months after surgery, she experienced an episode of cervical stenosis. The hematometra was drained by manual dilation using Hegar dilators at the bedside. Subsequently, she has experienced regular monthly menstruation for 8 months postoperatively. 


\section{Discussion}

In our cohort, the most common presenting symptom was primary amenorrhoea. The patients presented at mean age $16.7 \pm 2.4$ years, which is the appropriate time for consultation for primary amenorrhoea. This indicated that the young women and their caregivers did not seek to delay treatment for this gynaecological problem. Moreover, the healthcare providers referred the young women at the appropriate age.

The diagnosis of MRKH syndrome is mainly based on clinical assessment. Ultrasound can be a useful modality to confirm the absence of a uterus because of its relatively low cost, non-invasive nature, and widespread availability in many gynaecology units. However, the effectiveness of ultrasound is operator-dependent and image quality can be affected by each patient's body build. Although threedimensional ultrasound is useful for assessment of Müllerian anomalies, ${ }^{14,15}$ it may not be necessary to detect the absence of a uterus. Magnetic resonance imaging is another useful modality, with good soft tissue resolution; it allows good visualisation of any rudimentary horns, possible endometrium, and ovaries. Magnetic resonance imaging reportedly exhibited $100 \%$ sensitivity when diagnostic laparoscopy was performed in women with uterine anomalies $^{14,16}$; therefore, diagnostic laparoscopy is rarely required or recommended for the diagnosis of MRKH syndrome. Even in patients with acute hematometra of the obstructing uterus, conservative treatment might be appropriate if the diagnosis of MRKH syndrome is made prior to surgery. In our cohort, a patient with acute hematometra presented to the surgical unit and received a provisional diagnosis of acute appendicitis. In women with congenital androgen insensitivity syndrome, the absence of a uterus can be a similar finding ${ }^{5}$; however, clinical examination of women with congenital androgen insensitivity syndrome has shown that these patients do not have axillary hair or pubic hair, and a simple karyotype analysis can be used to differentiate between the two possible diagnoses.

Psychological concerns can be an important factor in patients with MRKH syndrome. These patients can develop a negative self-image because they perceive themselves to be different from their peers; they can also develop low self-esteem. ${ }^{17-19}$ Upon diagnosis and treatment, the patients and their caregivers should be offered guidance and psychological support. ${ }^{20}$ Resources should be allocated for provision of psychological services, which is an essential component of multidisciplinary care. Although our service has been available for many years, more services of this type are needed in the future.

The creation of a neovagina is an important aspect of treatment for patients with MRKH syndrome. Various neovagina creation techniques have been described over the years. A non-surgical method involving the utilisation of handheld vaginal dilators was first described by Frank in $1938 .^{21}$ Ingram $^{22}$ later modified the technique with the use of a bicycle stool. The respective success rates for Frank's and Ingram's methods are reportedly $66 \%$ to $95 \%$,6,9,23-25 and $92 \% .{ }^{22}$ Despite the success of these non-surgical techniques, various surgical techniques have also been developed for vaginoplasty. These include the McIndoe technique, usage of various grafts (eg, amnion, skin, or bowel), the Davydov technique, and the Vecchietti technique. However, these surgical techniques may result in some complications. Following intestinal vaginoplasty, introital stenosis and vaginal discharge can occur in up to $9 \%$ and $7 \%$ of patients, respectively. ${ }^{5,7,26-28}$ There have also been case reports regarding the onset of adenocarcinoma in bowel grafts ${ }^{29,30}$ and the onset of hair growth or squamous cell carcinoma in skin grafts. ${ }^{31}$ Following the use of the Davydov technique (ie, downward stretching of the pelvic peritoneum to create a vagina), neovaginal vault granulation can occur in up to $8 \%$ of patients. ${ }^{5,7}$ Intra-operative bladder injury can occur in $1 \%$ to $2 \%$ of patients who undergo the Vecchietti procedure, which comprises progressive upward stretching of the perineal skin by means of threads that exit from the anterior abdominal wall. ${ }^{5,732}$ Strictures and contractures are also a concern in patients who undergo any surgical technique; therefore, a mould or dilation is often required during the early postoperative period. A relatively longer hospital stay of 2 to 9 days is a notable concern following surgical vaginoplasty., Given its lower risk for potential complications and high success rate, VD has become the first-line technique for the creation of a neovagina in Australia, the United Kingdom, the United States, and parts of Russia. ${ }^{7}$ Previous studies have also demonstrated that VD is more cost-effective, compared with firstline surgical treatment. ${ }^{5,33}$

Edmonds et $\mathrm{al}^{9}$ reported an average of 5 months to achieve satisfactory vaginal length, which they defined as $6 \mathrm{~cm}$, or when the patient is able to achieve satisfactory sexual coitus; our results were comparable (ie, 4 months). The mean vaginal length of $6.9 \mathrm{~cm}$ achieved in our cohort was also comparable with the findings in previous studies. ${ }^{7,9,23,25}$ Generally, VD results in a shorter average vaginal length, compared with surgical vaginoplasty. ${ }^{5,7}$ Notably, $6.6 \mathrm{~cm}$ has been proposed as the ideal vaginal length for satisfactory sexual activity. ${ }^{7,24}$ Of the patients who completed VD therapy in our cohort, $92.3 \%$ reported satisfactory coitus. This success rate was comparable to the $94.9 \%$ reported by Edmonds et al, ${ }^{9}$ who published the largest study regarding VD thus far.

Sexual coitus has been shown to successfully create a neovagina $^{9,34,35}$; this outcome was achieved 
by a few patients in our cohort. Importantly, previous coital attempts in our patients did not affect the starting width and length of the vagina, or the interval required to complete the dilation. This is presumably because the patients abandoned further coital attempts after unsuccessful coitus.

A common cause for the failure of VD is a lack of motivation. ${ }^{36}$ The success rate was high among patients in our cohort. Roberts et $\mathrm{al}^{37}$ reported that women younger than 18 years of age at the initiation of therapy had a significantly higher failure rate. The mean age of patients in our group was 24 years; most patients $(79 \%)$ were in a relationship before initiation of therapy (data not shown), which might have enhanced their motivation to complete the therapy. Accordingly, we only commence VD therapy when patients are well prepared for this therapy, such that they fully understand the importance of compliance.

Following the creation of a neovagina, regular coitus or dilation is required to maintain it. Three patients in our cohort required a second course of VD because they experienced shrinkage of the neovagina after discontinuation of self-dilation and cessation of regular coitus. However, a short duration of therapy was required to re-establish a satisfactory neovagina. Notably, vaginal spotting occurred in four patients during VD therapy. In all patients, spotting resolved with conservative management or with local application of oestrogen cream to the neovagina.

This study demonstrated the characteristics and treatment of Chinese patients with an uncommon condition, MRKH syndrome, as well as the outcome of VD therapy in those patients. The study may have been limited by the small number of patients, which is attributable to the rarity of MRKH syndrome. In addition, standardised validated questionnaires were not employed to assess sexual function among the patients in this study. Future research using validated questionnaires should be performed to assess the psychological aspects of these patients before, during, and after VD therapy.

\section{Conclusion}

Mayer-Rokitansky-Küster-Hauser syndrome is an uncommon gynaecological condition. Careful treatment by healthcare providers familiar with this condition may aid patients in achieving suitable outcomes. Vaginal dilation therapy is an effective first-line treatment for the creation of a neovagina. The results achieved in our cohort of Chinese women are comparable with the findings in previously published studies in other nations. However, long-term data collection, including the use of validated questionnaires, will provide more objective information regarding sexual function in patients with MRKH syndrome.

\section{Author contributions}

All authors had full access to the data, contributed to the study, approved the final version for publication, and take responsibility for its accuracy and integrity.

Concept or design: K Ng, SSC Chan.

Acquisition of data: K Ng, SSC Chan, KW Yiu.

Analysis or interpretation of data: K Ng, SSC Chan.

Drafting of the manuscript: $\mathrm{K} \mathrm{Ng}$, SSC Chan.

Critical revision of the manuscript for important intellectual content: All authors.

\section{Conflicts of interest}

As an editor of the journal, JPW Chung was not involved in the peer review process. Other authors have disclosed no conflicts of interest.

\section{Funding/support}

This research received no specific grant from any funding agency in the public, commercial, or not-for-profit sectors.

\section{Ethics approval}

This study was approved by The Joint Chinese University of Hong Kong-New Territories East Cluster Clinical Research Ethics Committee (Ref CRE.2020.023). The requirement for written informed consent was waived.

\section{References}

1. Creighton SM. Long-term sequelae of genital surgery. In: Balen AH, Creighton SM, Davies MC, MacDougall J, Stanhope R, editors. Paediatric and Adolescent Gynaecology: A Multidisciplinary Approach. Cambridge: Cambridge University Press; 2004.

2. Morcel K, Camborieux L, Programme de Recherches sur les Aplasies Müllériennes, Guerrier D. Mayer-RokitanskyKuster-Hauser (MRKH) syndrome. Orphanet J Rare Dis 2007;2:13.

3. Oppelt P, Renner SP, Kellermann A, et al. Clinical aspects of Mayer-Rokitansky-Kuester-Hauser syndrome: recommendations for clinical diagnosis and staging. Hum Reprod 2006;21:792-7.

4. Laufer MR. Congenital absence of the vagina: in search of the perfect solution. When, and by what technique, should a vagina be created? Curr Opin Obstet Gynecol 2002;14:441-4.

5. Callens N, De Cuypere G, De Sutter P, et al. An update on surgical and non-surgical treatments for vaginal hypoplasia. Hum Reprod Update 2014;20:775-801.

6. Ismail-Pratt IS, Bikoo M, Liao LM, Conway GS, Creighton SM. Normalization of the vagina by dilator treatment alone in complete androgen insensitivity syndrome and Mayer-Rokitansky-Kuster-Hauser syndrome. Hum Reprod 2007;22:2020-4.

7. McQuillan SK, Grover SR. Dilation and surgical management in vaginal agenesis: a systematic review. Int Urogynecol J 2014;25:299-311.

8. Committee on Adolescent Health Care. Committee opinion no. 562: Müllerian agenesis: diagnosis, management, and treatment. Obstet Gynecol 2013;121:1134-7.

9. Edmonds DK, Rose GL, Lipton MG, Quek J. MayerRokitansky-Kuster-Hauser syndrome: a review of 245 consecutive cases managed by a multidisciplinary approach 
with vaginal dilators. Fertil Steril 2012;97:686-90.

10. Qin C, Luo G, Du M, et al. The clinical application of laparoscope-assisted peritoneal vaginoplasty for the treatment of congenital absence of vagina. Int J Gynaecol Obstet 2016;133:320-4.

11. Chan SS, Yiu KW, Yuen PM, Sahota DS, Chung TK. Menstrual problems and health-seeking behaviour in Hong Kong Chinese girls. Hong Kong Med J 2009;15:1823.

12. Yiu KW, Chan SS, Chung TK. Mothers' attitude to the use of a combined oral contraceptive pill by their daughters for menstrual disorders or contraception. Hong Kong Med J 2017;23:150-7.

13. Zacharin RF. A Chinese anatomy-The pelvic supporting tissues of Chinese and Occidental female compared and contrasted. Aust Nz J Obstet Gyn 1977;17:1-11.

14. Deutch TD, Abuhamad AZ. The role of 3-dimensional ultrasonography and magnetic resonance imaging in the diagnosis of Mullerian duct anomalies: a review of the literature. J Ultrasound Med 2008;27:413-23.

15. Ahmadi F, Haghighi H. Detection of congenital Mullerian anomalies by real-time 3D sonography. J Reprod Infertil 2012;13:65-6.

16. Pellerito JS, McCarthy SM, Doyle MB, Glickman MG, DeCherney AH. Diagnosis of uterine anomalies: relative accuracy of MR imaging, endovaginal sonography, and hysterosalpingography. Radiology 1992;183:795-800.

17. Heller-Boersma JG, Edmonds DK, Schmidt UH. A cognitive behavioural model and therapy for utero-vaginal agenesis (Mayer-Rokitansky-Kuster-Hauser syndrome: MRKH). Behav Cogn Psychother 2009;37:449-67.

18. Heller-Boersma JG, Schmidt UH, Edmonds DK. Psychological distress in women with uterovaginal agenesis (Mayer-Rokitansky-Kuster-Hauser Syndrome, MRKH). Psychosomatics 2009;50:277-81.

19. Patterson CJ, Crawford R, Jahoda A. Exploring the psychological impact of Mayer-Rokitansky-KusterHauser syndrome on young women: an interpretative phenomenological analysis. J Health Psychol 2016;21:122840.

20. Wagner A, Brucker SY, Ueding E, et al. Treatment management during the adolescent transition period of girls and young women with Mayer-Rokitansky-KusterHauser syndrome (MRKHS): a systematic literature review. Orphanet J Rare Dis 2016;11:152.

21. Frank R. The formation of an artificial vagina without operation. Am J Obstet Gynecol 1938;35:1053-5.

22. Ingram JM. The bicycle seat stool in the treatment of vaginal agenesis and stenosis: a preliminary report. Am J Obstet Gynecol 1981;140:867-73.

23. Bach F, Glanville JM, Balen AH. An observational study of women with Mullerian agenesis and their need for vaginal dilator therapy. Fertil Steril 2011;96:483-6.

24. Callens N, De Cuypere G, Wolffenbuttel KP, et al. Long- term psychosexual and anatomical outcome after vaginal dilation or vaginoplasty: a comparative study. J Sex Med 2012;9:1842-51.

25. Ketheeswaran A, Morrisey J, Abbott J, Bennett M, Dudley J, Deans R. Intensive vaginal dilation using adjuvant treatments in women with Mayer-Rokitansky-KusterHauser syndrome: retrospective cohort study. Aust N Z J Obstet Gynaecol 2018;58:108-13.

26. Kölle A, Taran FA, Rall K, Schöller D, Wallwiener D, Brucker SY. Neovagina creation methods and their potential impact on subsequent uterus transplantation: a review. BJOG 2019;126:1328-35.

27. Cai B, Zhang JR, Xi XW, Yan Q, Wan XP. Laparoscopically assisted sigmoid colon vaginoplasty in women with MayerRokitansky-Kuster-Hauser syndrome: feasibility and short-term results. BJOG 2007;114:1486-92.

28. Darai E, Toullalan O, Besse O, Potiron L, Delga P. Anatomic and functional results of laparoscopic-perineal neovagina construction by sigmoid colpoplasty in women with Rokitansky's syndrome. Hum Reprod 2003;18:2454-9.

29. Hiroi $H$, Yasugi $T$, Matsumoto $K$, et al. Mucinous adenocarcinoma arising in a neovagina using the sigmoid colon thirty years after operation: a case report. J Surg Oncol 2001;77:61-4.

30. Kita Y, Mori S, Baba K, et al. Mucinous adenocarcinoma emerging in sigmoid colon neovagina 40 years after its creation: a case report. World J Surg Oncol 2015;13:213.

31. Idrees MT, Deligdisch L, Altchek A. Squamous papilloma with hyperpigmentation in the skin graft of the neovagina in Rokitansky syndrome: literature review of benign and malignant lesions of the neovagina. J Pediatr Adolesc Gynecol 2009;22:e148-55.

32. Brucker SY, Gegusch M, Zubke W, Rall K, Gauwerky JF, Wallwiener D. Neovagina creation in vaginal agenesis: development of a new laparoscopic Vecchietti-based procedure and optimized instruments in a prospective comparative interventional study in 101 patients. Fertil Steril 2008;90:1940-52.

33. Routh JC, Laufer MR, Cannon GM Jr, Diamond DA, Gargollo PC. Management strategies for MayerRokitansky-Kuster-Hauser related vaginal agenesis: a costeffectiveness analysis. J Urol 2010;184:2116-21.

34. D'Alberton A, Santi F. Formation of a neovagina by coitus. Obstet Gynecol 1972;40:763-4.

35. Moen MH. Creation of a vagina by repeated coital dilatation in four teenagers with vaginal agenesis. Acta Obstet Gynecol Scand 2000;79:149-50.

36. Liao LM, Doyle J, Crouch NS, Creighton SM. Dilation as treatment for vaginal agenesis and hypoplasia: a pilot exploration of benefits and barriers as perceived by patients. J Obstet Gynaecol 2006;26:144-8.

37. Roberts CP, Haber MJ, Rock JA. Vaginal creation for Mullerian agenesis. Am J Obstet Gynecol 2001;185:134952 . 